\title{
RUUSUKAALIN SÄILYTYS JA SEN C-VITAMIINIPITOISUUS
}

\author{
IRMA SUHONEN \\ Helsingin yliopiston puutarhatieteen laitos, Viik
}

Saapunut 16. 3. 1967

Ruusukaalia viljellään maassamme vain vähän, vaikka se energia- ja vitamiinipitoisuutensa puolesta on parhaita kaalilajeja. Lisäksi sitä pidetään erittäin herkullisena. Ruusukaalin vaatiman pitkän kasvukauden takia vain harvat lajikkeet soveltuvat oloihimme ja niilläkin huhti- ja toukokuussa tapahtuvasta esikasvatuksesta huolimatta pääsato valmistuu vasta syys- ja lokakuussa (SALOKANGAS \& Isotalo 1963). Epäedullisina kasvukausina havaitaan usein, kuinka osa silmuista ei ehdi valmistua ennen talven tuloa. Edullisena kasvukautena taas saattaa sato olla runsas, mutta silmujen myöhäinen ja yhtäaikainen valmistuminen aiheuttaa tuoteruuhkaa, minkä vuoksi on mahdotonta markkinoida tai käyttää satoa heti. On siis pyrittävä säilyttämään tuote myynti- ja käyttökelpoisena jopa kuukausien ajan.

Ruusukaali sietää verraten hyvin lieviä pakkasia, niinpä Etelä-Ruotsissa sitä voidaan talvehdittaa kasvupaikallaan, mistä satoa korjataan koko talven ajan (LAmm et al. 1958), joskin "varastointitappiot» tällöin saattavat olla suuret (ÅvALL 1963). Suomessa tämänlaatuinen säilytys on paikallaan vain kotitarvetta varten. Pellolta lumen sisästä jäätyneinä poimitut ruusukaalin silmut ovat heti käytettyinä mitä maukkaimpia. Siellä, missä lunta on runsaasti ja tästä syystä vaikeuksia kaalien esiin kaivamisessa, annetaan niiden jäätyä paikallaan. Ennen runsaita lumisateita ne korjataan kylmään vajaan, mistä voidaan jäätyneitä silmuja tarpeen mukaan ottaa käyttöön.

Jäätyneinä säilytetty ruusukaali pehmenee ja pilaantuu kuitenkin nopeasti sulamisen jälkeen. Tämä estää jäätyneenä säilytyksen myyntiä varten. Siksi varastoidaan myyntiä varten viljelty ruusukaali noin $0^{\circ}$ :n lämpötilassa joko niin, että kasvit kokonaan varastoidaan tai vain silmut poimitaan ja varastoidaan. Ensin mainittu varastoimismenetelmä on edullinen sen puolesta, että runsaasti työtä vaativa poiminta voidaan silloin suorittaa vasta syksyisten korjuutöiden päätyttyä. 
Toisaalta ruusukaalin varret vaativat runsaasti tilaa varastossa. Valmiiksi poimittujen silmujen tilantarve säilytyksessä ei taas ole suuri. Molemmissa menetelmissä on vaikeutena silmuista varastointiaikana tapahtuva runsas haihdunta ja herkkä pilaantuminen. Niinpä Alnarpissa Åvall (1963) totesi puhdistus- ja haihtumistappioiden olevan kaksiviikkoisen $2^{\circ}$ :ssa säilytyksen jälkeen $20 \%$ alkuperäisestä painosta.

Koska ruusukaalin varastointitutkimuksia aikaisemmin oli tehty vain vähän, ja nekin suurimmaksi osaksi koskettivat lyhyttä varastointia varten suoritettavaa esikäsittelyä, ryhdyttiin Helsingin yliopiston puutarhatieteen laitoksella v. 1962 selvittämään ruusukaalin silmujen varastointia. Tutkimuksessa keskityttiin eri laisten säilytyslämpötilojen ja pakkausten soveltuvuuden sekä askorbiinihappopitoisuuden selvitykseen. Tulokset esikäsittelyä koskevista tutkimuksista on julkaistu aikaisemmin (VoIPIo 1966).

\section{Aineisto ja menetelmät}

Tutkimukseen tarvittava ruusukaaliaineisto (lajikkeet Jade $\mathrm{F}_{1}$ ja Long Island) kasvatettiin Viikissä Puutarhatieteen laitoksen koekentällä. Kylvö suoritettiin $2-3.5$, ist utus avomaalle 28. 5.-12. 6. ja sadonkorjuu 1-4. 10. Viljelymenetelmät olivat tavanomaiset (Pieni vihannesviljelyn opas 1964).

Heti sadonkorjuun jälkeen $10-15 \mathrm{~g}: \mathrm{n}$ painoiset silmut kunnostettiin poistamalla löyhät suojuslehdet. Silmut pakattiin laatikoihin tai $270 \times 113 \times 55 \mathrm{~mm}$ : mittaisiin MSAT-pusseihin, joihin tehtiin 16 halkaisijaltaan $5 \mathrm{~mm}: \mathrm{n}$ suuruista pyöreää reikää. Kussakin koejäsenessä oli 5 kerrannetta.

Kunnostuksen ja pakkauksen jälkeen silmut vietiin viiteen eri koekellariin, joissa lämpötilat olivat $1-2^{\circ}, 0-1^{\circ},-1.5-0^{\circ},-2.5 \pm 0.5^{\circ} \mathrm{ja}-5 \pm 0.5^{\circ}$. Varastojen ilman suhteellinen kosteus oli $85-95 \%$. Ruusukaalieriä varastoitiin 30,60 ja 120 vrk:n pituiset ajat. Säilytyksen jälkeen silmut punnittiin ja arvosteltiin.

Askorbiinihappo- ja kuiva-ainemääritykset tehtiin sadonkorjuun yhteydessä sekä varastoinnin päätyttyä. Askorbiinihappo määritettiin amylasetaattiekstrahointimetodin formaldehydimuunnosta käyttäen (FujITA \& NumatA 1941, RoBINSON \& Stotz 1945, ERKAma 1946). Silmujen kuiva-aine määritettiin kuivaamalla näytteitä 24 tunnin ajan $105^{\circ}$ :ssa.

\section{Tulokset}

Vuonna 1962 tutkittiin alustavasti sellofaanikelmun merkitystä ruusukaalin varastoinnissa. Tällöin todettiin rei'itetyn kelmun ehkäisevän haihduntaa niin, että sellofaanikelmuun pakattujen silmujen haihtumishäviö oli vain neljännes avonaisiin laatikoihin pakattujen silmujen haihtumishäviöstä. Koska oli ilmeistä, että rei'itetty kelmu on edullinen pakkausaine varastoitaessa, suoritettiin asiasta jatkokokeita v. $1964-66$. Tulokset näistä tutkimuksista esitetään taulukossa 1 .

Kun ruusukaalia varastoitiin avonaisissa laatikoissa 30 vuorokautta tai sitä kauemmin, olivat silmut lämpötilasta riippumatta nahistuneita. Haihtumistappio oli yli $15 \%$, mistä syystä ruusukaali ei enää ollut kauppakelpoista. Sekä $-2.5^{\circ}$ :ssa että $-5^{\circ}$ :ssa säilytetyt erät pehmenivät sulaessaan. 
Taulukko 1. Ruusukaalin ( Jade $\mathrm{F}_{1}=\mathrm{J}$ ja Long Island $=\mathrm{L}$ ) varastointi laatikoihin ja MSAT-pusseihin pakattuna v. $1964-66$.

Table 1. Effect of storage temperature and way of packing on the weight loss of Brussels sprouts (Jade $F_{1}$ $=J$, Long Island $=L$ ) in 1964-66.

\begin{tabular}{|c|c|c|c|c|c|}
\hline \multirow{3}{*}{$\begin{array}{c}\text { Varastointitapa ja } \\
\text {-lämpötila }{ }^{\circ} \mathrm{C} \\
\text { Packing and } \\
\text { storage temperature }{ }^{\circ} \mathrm{C}\end{array}$} & \multirow{3}{*}{$\begin{array}{l}\text { Varastointi- } \\
\text { kausi } \\
\text { Storage } \\
\text { season }\end{array}$} & \multirow{3}{*}{$\begin{array}{l}\text { Lajike } \\
\text { Variety }\end{array}$} & \multicolumn{3}{|c|}{$\begin{array}{l}\text { Paino (\% alkuperäisestä) varastoin- } \\
\text { nin jatkuttua }\end{array}$} \\
\hline & & & \multicolumn{3}{|c|}{$\begin{array}{c}\text { Weight of Brussels sprouts ( } \% \text { from } \\
\text { original weight) after storage }\end{array}$} \\
\hline & & & $\begin{array}{l}30 \text { vrk } \\
30 \text { days }\end{array}$ & $\begin{array}{l}\text { period of } \\
60 \text { vrk } \\
60 \text { days }\end{array}$ & $\begin{array}{l}120 \text { vrk } \\
120 \text { days }\end{array}$ \\
\hline Laatikko & $1964-65$ & $\mathrm{~J}$ & $78.7 \pm 2.9$ & $61.1 \pm 4.3$ & - \\
\hline Open box & 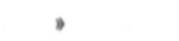 & L & $82.3 \pm 0.6$ & $64.3 \pm 1.7$ & - \\
\hline$A^{2}$ & $1965-66$ & $\mathrm{~J}$ & $84.5 \pm 0.5$ & $69.8 \pm 2.5$ & - \\
\hline $0-1$ & $1965-66$ & J & $76.8 \pm 2.3$ & $50.1 \pm 2.5$ & $33.0 \pm 2.9$ \\
\hline$-1.5-0$ & $1964-65$ & $\mathrm{~J}$ & - & $68.8 \pm 2.0$ & $47.4 \pm 4.3$ \\
\hline & 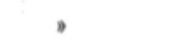 & $\mathrm{L}$ & - & $69.8 \pm 2.3$ & $47.8 \pm 4.4$ \\
\hline-2.5 & $1964-65$ & $\mathrm{~J}$ & - & $75.1 \pm 1.6^{*}$ & $63.3 \pm 1.9^{*}$ \\
\hline & 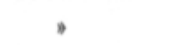 & $\mathrm{L}$ & - & $75.3 \pm 1.0^{*}$ & $61.6 \pm 3.3^{*}$ \\
\hline & $1965-66$ & $\mathrm{~J}$ & $74.1+4.2$ & $55.4 \pm 7.2^{*}$ & $46.6 \pm 5.6^{*}$ \\
\hline-5 & $1964-65$ & $\mathrm{~J}$ & - & $78.3 \pm 1.8^{*}$ & $60.8 \pm 1.3^{*}$ \\
\hline & , & L & - & $82.3 \pm 3.4^{*}$ & $68.1 \pm 1.3^{*}$ \\
\hline MSAT & $1964-65$ & $\mathbf{J}$ & $95.9 \pm 0.7$ & $93.5 \pm 0.5$ & - \\
\hline$M S A T-b a g$ &, & L & $95.7 \pm 1.5$ & $92.2 \pm 0.8$ & - \\
\hline & $1965-66$ & $\mathrm{~J}$ & $95.8 \pm 0.3$ & $90.7 \pm 1.0$ & - \\
\hline & , & $\mathrm{L}$ & $96.4 \pm 0.6$ & $91.0 \pm 0.8$ & - \\
\hline $0-1$ & $1965-66$ & $\mathrm{~J}$ & $94.8 \pm 0.2$ & $90.2 \pm 1.0$ & $83.6 \pm 0.8$ \\
\hline & 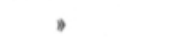 & $\mathrm{L}$ & $94.9 \pm 1.0$ & $91.6 \pm 1.0$ & $83.9 \pm 4.6$ \\
\hline$-1.5-0$ & $1964-65$ & $\mathbf{J}$ & - & $93.7 \pm 0.5$ & $88.6 \pm 1.3$ \\
\hline & , & $\mathrm{L}$ & - & $93.3 \pm 0.5$ & $83.7 \pm 5.1$ \\
\hline-2.5 & $1964-65$ & $\mathrm{~J}$ & - & $94.2 \pm 0.6$ & $91.1 \pm 1.3$ \\
\hline & , & L & - & $94.6 \pm 0.2$ & $90.4 \pm 2.4$ \\
\hline & $1965-66$ & $\mathrm{~J}$ & $94.4 \pm 0.8$ & $89.1 \pm 1.5$ & $82.0 \pm 2.6$ \\
\hline & , & $\mathrm{L}$ & $\mathbf{9 4 . 1} \pm 0.5$ & $90.1 \pm 2.5$ & $81.8 \pm 0.3$ \\
\hline-5 & $1964-65$ & $\mathrm{~J}$ & - & $96.2 \pm 0.6^{*}$ & $92.4 \pm 0.5^{*}$ \\
\hline & , & $\mathrm{L}$ & - & $96.4 \pm 0.8^{*}$ & $92.0 \pm 0.6^{*}$ \\
\hline
\end{tabular}

Sellofaanipusseissa säilytettiin $-2.5^{\circ},-1.5-1^{\circ}$ ja $1-2^{\circ}$ :ssa ruusukaalia 30 vrk:n ajan, minkä jälkeen kaikki erät olivat kauppakelpoisia ja haihtumishäviö vain $5 \%$. Eri lämpötiloissa haihtumistappiot eivät sanottavasti poikenneet toisistaan. 60 vrk:n pituisen säilytyksen jälkeen olivat uloimmat suojuslehdet $1-2^{\circ}$ :ssa varastoiduissa erissä osittain kellastuneita ja homehtuneita. Sen sijaan $-2.5^{\circ}$ :ssa sekä $-1.5-1^{\circ}$ :ssa varastoiduissa erissä ei kellastumista tai homehtumista ilmennyt ja erät olivat kauppakelpoisia. Näiden erien haihtumistappio vaihteli 5 :stä $11 \%$ :iin, eikä sulamisen jälkeistä silmujen pehmenemistä esiintynyt. Säilytyslämpötilan 
Taulukko 2. MSAT-pusseissa säilytetyn ruusukaalin askorbiinihappo- (mg \% tuorepainosta) ja kuivaainepitoisuus $(\%)$ v. 1964-66. Jade $F_{1}=\mathrm{J}$, Long Island $=\mathrm{L}$.

Table 2. Ascorbic acid ( $m$ g \% fresh weight) and dry matter content ( $\%$ ) of Brussels sprouts stored in MSATbags in 1964-66. Jade $F_{1}=J$, Long Island $=L$.

\begin{tabular}{|c|c|c|c|c|c|c|c|c|}
\hline \multirow{2}{*}{$\begin{array}{l}\text { Varastointilämpö- } \\
\text { tila }{ }^{\circ} \mathrm{C} \\
\text { Storage temperature } \\
{ }^{\circ} \mathrm{C}\end{array}$} & \multirow{2}{*}{$\begin{array}{l}\text { Varastointi- } \\
\text { kausi } \\
\text { Storage } \\
\text { season }\end{array}$} & \multirow{2}{*}{$\begin{array}{l}\text { Lajike } \\
\text { Variety }\end{array}$} & \multicolumn{4}{|c|}{$\begin{array}{l}\text { Varastoinnin pituus } \\
\text { Length of storage } \\
60 \text { vrk } \\
60 \text { days }\end{array}$} & \multicolumn{2}{|c|}{$\begin{array}{l}120 \text { vrk } \\
120 \text { days }\end{array}$} \\
\hline & & & $\begin{array}{l}\text { ask.h. } \\
\text { asc. } \\
\text { acid } \\
\text { mg \% }\end{array}$ & $\begin{array}{l}\text { ka. } \\
\text { dry } \\
\text { mat. } \\
\%\end{array}$ & $\begin{array}{l}\text { ask.h. } \\
\text { asc. } \\
\text { acid } \\
\mathrm{mg} \%\end{array}$ & $\begin{array}{l}\text { ka. } \\
\text { dry } \\
\text { mat. } \\
\%\end{array}$ & $\begin{array}{l}\text { ask.h. } \\
\text { asc. } \\
\text { acid } \\
\text { mg \% }\end{array}$ & $\begin{array}{c}\text { ka. } \\
\text { dry } \\
\text { mat. } \\
\%\end{array}$ \\
\hline \multirow[t]{5}{*}{$1-2$} & $1964-65$ & $\mathrm{~J}$ & 163 & 16.3 & 125 & 16.2 & - & - \\
\hline & , & L & 211 & 16.6 & 169 & 15.7 & - & - \\
\hline & $1965-66$ & $\mathrm{~J}$ & 99 & 16.4 & 82 & 15.2 & - & - \\
\hline & , & L & 82 & 15.7 & 87 & 13.4 & - & - \\
\hline & & & 139 & 16.3 & 116 & 15.1 & - & - \\
\hline \multirow[t]{5}{*}{$-1.5-1$} & $1964-65$ & $\mathrm{~J}$ & - & - & 126 & 16.1 & 45 & 15.3 \\
\hline & , & L & - & - & 165 & 17.3 & 143 & 16.3 \\
\hline & $1965-66$ & $\mathbf{J}$ & 79 & 15.1 & 67 & 16.3 & 68 & 15.4 \\
\hline & , & L & 88 & 15.0 & 91 & 14.3 & 78 & 15.5 \\
\hline & & & & & 112 & 16.0 & 84 & 15.6 \\
\hline \multirow[t]{5}{*}{-2.5} & $1964-65$ & $\mathbf{J}$ & - & - & 83 & 15.0 & 63 & 16.1 \\
\hline & , & L & - & - & 101 & 15.3 & 69 & 13.8 \\
\hline & $1965-66$ & $\mathrm{~J}$ & 77 & 15.5 & 59 & 15.8 & 64 & 16.5 \\
\hline & , & L & 77 & 14.8 & 92 & 14.5 & 58 & 15.9 \\
\hline & & & & & 84 & 15.2 & 64 & 15.6 \\
\hline \multirow[t]{5}{*}{-5} & $1964-65$ & $\mathbf{J}$ & - & - & 43 & 16.3 & 5 & 14.8 \\
\hline & 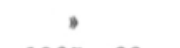 & L & - & - & 41 & 17.0 & 2 & 16.8 \\
\hline & $1965-66$ & $\mathbf{J}$ & - & - & 21 & 16.1 & 2 & 15.0 \\
\hline & , & L & - & - & 19 & 15.0 & 1 & 15.9 \\
\hline & & & & & 31 & 16.3 & 3 & 15.4 \\
\hline \multirow[t]{4}{*}{-25} & $1964-65$ & $\mathrm{~J}$ & - & - & 37 & 16.7 & 34 & 15.6 \\
\hline & $1965-66$ & $\mathbf{J}$ & 35 & 15.4 & 14 & 16.2 & 16 & 15.6 \\
\hline & 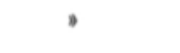 & L & 33 & 14.8 & 19 & 14.8 & 26 & 15.7 \\
\hline & & & & & 23 & 15.9 & 25 & 15.6 \\
\hline
\end{tabular}

oltua $-5^{\circ}$ sellofaanipussiin samoin kuin avolaatikoihin pakatut ruusukaalit pehmenivät sulaessaan. Varastoinnin jatkuttua 120 päivää olivat $-1.5-1^{\circ}$ :ssa säilytetyt silmut suurimmaksi osaksi mädänneitä, mutta $-2.5^{\circ}$ :ssa säilytetyt vielä käyttökelpoisia, joskin varastointikautena 1965 -66 nahistuneita. Sulamisen jälkeen näiden erien pintalehdissä esiintyi laikkuisuutta, muttei silmujen pehmenemistä.

Vuosina 1964 -66 suoritettiin ruusukaalin silmuista askorbiinihappo- sekä kuiva-ainemääritykset satoa korjattaessa ja kunkin varastointijakson päätyttyä. Satoa korjattaessa olivat silmujen askorbiinihappo- ja kuiva-ainepitoisuudet seuraavat: 
Jade $\mathrm{F}_{1}$

Long Island

$$
\begin{array}{r}
\text { ask.h.m } \\
127 \\
198
\end{array}
$$

ka. $\%$
16.2
16.4

$\begin{array}{cc}\text { ask.h.mg } \% & \text { ka. } \% \\ 99 & 15.8 \\ 106 & 15.9\end{array}$

Varastoinnin päätyttyä suoritettujen määritysten tuloksista nähdään (taulukko 2), että sellofaanipusseihin pakatun ruusukaalin kuiva-ainepitoisuus (13.4$17.3 \%$ ) oli varastoinnin pituudesta riippumaton tai että se hieman pieneni varastointiajan pidetessä. Sellofaanipusseissa olleiden silmujen arkorbiinihappopitoisuus pieneni varastointiajan pidetessä, ja aleneminen oli sitä nopeampaa, mitä alhaisempi lämpötila varastossa oli. Niinpä 60 vrk:n kuluttua $1-2^{\circ}$ :ssa säilytettyjen silmujen arkorbiinihappopitoisuus oli keskimäärin $116 \mathrm{mg} \%,-1.5-1^{\circ}$ :ssa $112 \mathrm{mg} \%$, $-2.5^{\circ}$ :ssa $84 \mathrm{mg} \%$ sekä $-5^{\circ}$ :ssa $31 \mathrm{mg} \%$. Vertailun vuoksi tutkittiin myös ryöppäämättömänä ${ }^{1}$ pakastetun ruusukaalin askorbiinihappopitoisuus. Myös näissä erissä arkorbiinihappopitoisuus aleni nopeasti (taulukko 2).

\footnotetext{
${ }^{1}$ Ryöppäyksellä tarkoitetaan pakastettavan tuotteen kuumentamista muutamiksi minuteiksi $80-100^{\circ}$ :seen.
}

Taulukko 3. Laatikoissa säilytetyn ruusukaalin askorbiinihappo- (mg \% tuorepainosta) ja kuiva-ainepitoisuus $(\%)$ v. 1964-66. Jade $\mathrm{F}_{1}=\mathrm{J}$, Long Island $=\mathrm{L}$.

Table 3. Ascorbic acid ( $m g \%$ fresh weight) and dry matter content ( $\%)$ of Brussels sprouts stored in open

\begin{tabular}{|c|c|c|c|c|c|c|c|c|}
\hline \multirow{2}{*}{$\begin{array}{l}\text { Varastointilämpö- } \\
\text { tila }{ }^{\circ} \mathrm{C} \\
\text { Storage temperature } \\
{ }^{\circ} \mathrm{C}\end{array}$} & \multirow{2}{*}{$\begin{array}{l}\text { Varastointi- } \\
\text { kausi } \\
\text { Storage } \\
\text { season }\end{array}$} & \multirow{2}{*}{$\begin{array}{l}\text { Lajike } \\
\text { Variety }\end{array}$} & \multicolumn{4}{|c|}{$\begin{array}{c}\text { Varastoinnin pituus } \\
\text { Length of storage } \\
60 \text { vrk } \\
60 \text { days }\end{array}$} & \multicolumn{2}{|c|}{$\begin{array}{l}120 \text { vrk } \\
120 \text { days }\end{array}$} \\
\hline & & & $\begin{array}{l}\text { ask.h. } \\
\text { asc. } \\
\text { acid } \\
\text { mg \% }\end{array}$ & $\begin{array}{l}\text { ka. } \\
\text { dry } \\
\text { mat. } \\
\%\end{array}$ & $\begin{array}{l}\text { ask.h } \\
\text { asc. } \\
\text { acid } \\
\mathrm{mg} \%\end{array}$ & $\begin{array}{l}\text { ka. } \\
\text { dry } \\
\text { mat. } \\
\%\end{array}$ & $\begin{array}{l}\text { ask.h. } \\
\text { asc. } \\
\text { acid } \\
\mathrm{mg} \%\end{array}$ & $\begin{array}{l}\text { ka. } \\
\text { dry } \\
\text { mat. } \\
\%\end{array}$ \\
\hline \multirow[t]{4}{*}{$1-2$} & $1964-65$ & $\mathrm{~J}$ & 171 & 17.9 & 171 & 24.4 & - & - \\
\hline & , & L & 222 & 19.5 & 227 & 22.5 & - & - \\
\hline & $1965-66$ & $\mathbf{J}$ & 101 & 17.8 & 87 & 18.2 & - & - \\
\hline & & & 165 & 18.4 & 162 & 21.7 & - & - \\
\hline \multirow[t]{4}{*}{$-1.5-1$} & $1964-65$ & $\mathrm{~J}$ & - & - & 139 & 20.7 & 119 & 26.7 \\
\hline & , & $\mathrm{L}$ & - & - & 159 & 17.6 & 119 & 26.7 \\
\hline & $1965-66$ & $\mathrm{~J}$ & - & - & 88 & 17.9 & 62 & 29.6 \\
\hline & & & & & 129 & 18.7 & 100 & 27.7 \\
\hline \multirow[t]{4}{*}{-2.5} & $1964-65$ & $\mathrm{~J}$ & - & - & 98 & 18.5 & 44 & 21.8 \\
\hline & , & $\mathrm{L}$ & - & - & 94 & 18.3 & 56 & 22.6 \\
\hline & $1965-66$ & $\mathbf{J}$ & - & - & 81 & 17.7 & 90 & 26.7 \\
\hline & & & & & 91 & 18.2 & 63 & 23.7 \\
\hline \multirow[t]{3}{*}{-5} & $1964-65$ & $\mathbf{J}$ & - & - & 48 & 19.0 & 1 & 23.0 \\
\hline & 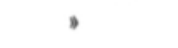 & L & - & - & 40 & 17.9 & 2 & 21.9 \\
\hline & & & & & 44 & 18.5 & 2 & 22.5 \\
\hline
\end{tabular}
boxes in 1964-66. Jade $F_{1}=J$, Long Island $=L$. 
Laatikoihin pakatun ruusukaalin kuiva-ainepitoisuus kasvoi varastointiajan pidetessä, samoin tuorepainosta laskettu askorbiinihappopitoisuus $1-2^{\circ}$ :ssa tapahtuneen 30 vrk:n pituisen säilytyksen jälkeen. Varastointiajan pidetessä silmujen askorbiinihappopitoisuus aleni sitä enemmän, mitä kylmempää varastossa oli (taulukko 3).

\section{Tulosten tarkastelu}

Edellä selostetuista tuloksista ilmenee, että ruusukaalin haihtumistappio jo kuukauden pituisessa varastoinnissa on niin suuri $(6-7 \%$ ensimmäisen varastointiviikon aikana $1-2^{\circ}$ :ssa, VoIPIO 1966), että kelmuun pakkaamisella saavutetaan huomattava hyöty. Niinpä sellofaanipusseihin pakatuissa erissä todettiin 30 vrk:n p.tuisen säilytyksen jälkeen $4-5 \%$ :n suuruinen painotappio. Kauppakelpoisena ruusukaali säilyy runsaasti rei'itettyihin sellofaanipusseihin pakattuna $1-2^{\circ}$ :ssa yli 30 vrk, $-2.5-1^{\circ}$ :ssa yli 60 vrk ja eräissä tapauksissa $-2.5^{\circ}$ :ssa käyttökelpoisena jopa 120 vrk.

Säilytyslämpötilan alentamista ruusukaalin jäätymispisteen, n. $-1.5^{\circ}$ :n, alapuolelle eivät laatikoihin pakatut ruusukaalit siedä. Sen sijaan sellofaanipussiin pakattu ruusukaali kestää hyvin säilytystilassa vallitsevaa $2.5^{\circ}$ :n pakkasta. Syy ilmenneeseen eroon lienee siinä, että silmujen hengityksessä kehittyvä lämpö säilyttää pakkauksen sisäisen ilman lämpimämpänä kuin varaston ilma.

MSAT-pusseissa rei’itys oli runsasta ja ilmeistä on, että niukempi rei’itys vähentäisi haihtumistappioita. Toisaalta rei'ityksen liiallinen supistaminen saattaa johtaa pakkauksen sisäisen ilman koostumuksen muuttumiseen hengityksen johdosta niin, että silmut tukehtuvat ja pilaantuvat. Åvallin (1957) ruusukaalilla suorittamien säilyvyystutkimusten mukaan huonosti kaasuja läpäisevä LSATkelmu täytyy rei’ittää. On kuitenkin huomattava, että kelmut läpäisevät eri tavoin kaasuja ja että ruusukaalin silmu tukehtuu vasta verraten alhaisessa happipitoisuudessa. Toмkınsin (1959) mukaan ruusukaalin silmut säilyvät hyvin, jopa tavallista paremmin kaasuvarastossa, jossa ilman hilididioksidipitoisuus on $15-16 \%$ ja happipitoisuus $5-6 \%$.

Askorbiinihapon määrää tutkittaessa todettiin, että Long Island-lajike sisältää sadonkorjuuaikana enemmän askorbiinihappoa kuin Jade $\mathrm{F}_{1}$. Havaittiin myös, että viileänä, kosteana kesänä kasvanut ruusukaali sisältää huomattavasti vähemmän askorbiinihappoa kuin kasvun kannalta edullisempana kesänä kasvanut.

Askorbiinihappopitoisuus alenee säilytyksessä sitä enemmän, mitä pitempi on säilytysaika, ja myös sitä nopeammin, mitä alhaisempi on varaston lämpötila. Yleinen käsitys, jonka mukaan askorbiinihappo säilyy sitä paremmin, mitä alhaisempi varastointilämpötila on, johtunee siitä, että suuri osa tutkimuksista on suoritettu jäätymispisteen yläpuolella olevissa lämpötiloissa säilytetyistä tuotteista Tiedetään kuitenkin, että arkorbiinihapon hajoamista kiihdyttävät entsyymit ovat vielä pakastuslämpötiloissakin aktiivisia, ja jollei entsyymien tuhoamiseksi suoriteta ryöppäystä, tapahtuu jään rikkomissa solukoissa nopeaa askorbiinihapon hajoamista. Viidessä pakkasasteessa, samoin kuin laatikoissa $-2.5^{\circ}$ :ssa säilytetyt ruusukaalit pehmenevät sulamisen jälkeen, mikä osoittaa jään palautumattomasti turmelleen silmujen solut. 
Kiinnostavaa oli huomata, että sellofaanipusseihin pakatut ruusukaalit $-2.5^{\circ}$ :ssa tapahtuneessa säilytyksessä menettivät enemmän askorbiinihappoa kuin korkeammissa lämpötiloissa säilytetyt, vaikka solukon rikkoutumisesta aiheutunutta silmujen pehmenemistä ei ilmennytkään.

\section{Ti ivistel $m \ddot{a}$}

Ruusukaalin silmujen varastointia ja askorbiinihapon säilyvyyttä niissä tutkittiin Helsingin yliopiston puutarhatieteen laitoksella v. 1962—66. Ruusukaali varastoitiin avonaisissa laatikoissa sekä rei'itetyissä MSAT-pusseissa.

Avonaisissa laatikoissa tapahtuu silmuista alhaisesta lämpötilasta $\left(-5-2^{\circ}\right)$ huolimatta niin suurta haihduntaa, että 30 vrk:n kuluttua erät ovat kauppaan kelpaamattomia.

MSAT-pusseissa haihtumistappio on 30 vuorokautta jatkuneen säilytyksen jälkeen $4-5 \%$ ja $-2.5-2^{\circ}$ :ssa varastoidut erät kauppakelpoisia.

60 :n säilytysvuorokauden jälkeen $1-2^{\circ}$ :ssa MSAT-pusseissa säilytetyt silmut ovat osittain kellastuneita ja homehtuneita, $-2.5-1^{\circ}$ :ssa säilytetyt kauppakelpoisia.

Laatikoissa $-2.5^{\circ}$ :ssa ja $-5^{\circ}$ :ssa sekä MSAT-pusseissa $-5^{\circ}$ :ssa varastoidut silmut pehmenevät sulaessaan.

Silmujen askorbiinihappopitoisuus satoa korjattaessa on $99-198 \mathrm{mg} \%$ tuorepainosta. Korkein askorbiinihappopitoisuus $227 \mathrm{mg} \%$ todettiin Long Island-lajikkeen silmuista, jotka olivat menettäneet $36 \%$ painostaan haihdunnan takia.

Silmujen askorbiinihappopitoisuus aleni säilytysajan pidetessä ja sitä nopeammin, mitä alhaisempi oli säilytyslämpötila.

\section{KIRJALLISUUS}

Erкама, J. 1946. Kolorimetrisestä C-vitamiinin määrityksestä 2.6-diklorfenolindofenolilla. Suom. Kemistilehti 19: 21-25.

Fujita, A. \& Numata, J. 1941. Ref. Gestirner, F. 1951. Chemischphysikalische Vitaminbestimmungsmetoden. 167 s. Stuttgart.

Lamm, R., Hinze, S. \& Ávall, H. 1958. Brysselkål. Medd. från stat. trädg. förs. 110: 23-25.

Pieni vihannesviljelyn opas. 1964. Puutarhaneuv, yhteistoim. julk. 17. $113 \mathrm{~s}$.

Robinson, W. \& Stotz, E. 1945. The indophenol-xylene extraction method for ascorbic acid and modifications for interfering substances. J. Biol. Chem. 160: 217-225.

Salokangas, K. \& Isotalo, A. 1963. Tuloksia ruusukaalin lajikekokeista Piikkiössä ja Rovaniemellä vuosina 1958-62. Ann. Agric. Fenn. 2: 180-193.

TомкіNs, R. G. 1959. The conditions for the gas storage of certain fruits and vegetables obtained by the use of a simple small scale method. Ditton Laboratory. Memoir. No. 4. 4 p.

VoIPIO, I. 1966. Kaalin esikäsittely varastointia varten. Maatal. ja Koetoim. 20: 133-140.

Åvalı, H. 1957. Brysselkål. Medd. från statens trädg. förs. 102: 23-25.

-1963 . Försök med brysselkâl. Ibid. 149: 32-35. 
S U M M A R Y :

COLD STORAGE AND ASCORBIC ACID CONTENT OF BRUSSELS SPROUTS

\author{
IRMA SUHONEN
}

Institute of Horticulture, University of Helsinki, Viik

In Finland, because of cold weather and snow one cannot keep Brussels sprouts overwintering on fields for marketing purposes. It is therefore necessary to store the late crop. In storage Brussels sprouts rapidly lose water and their quality. The rate of deterioration depends on the storage method.

In Viik, cold storage and the ascorbic acid content of Brussels sprouts were studied. The storage temperatures were $1-2,0-1,-1.5-0,-2.5 \pm 0.5$ and $-5 \pm 0.5{ }^{\circ} \mathrm{C}$ and the relative humidity $85-$ $95 \%$. The sprouts were packed in open boxes or in perforated MSAT-bags.

Results after storage of 30,60 and 120 days in 1964-66 are shown in Table 1. Accordingly Brussels sprouts packed in open boxes were no longer saleable after 30 days' storage because of wilting. Sprouts that were stored in MSAT-bags were saleable after 30 days' storage and the water loss was about $5 \%$ from the original weight. After 60 days' storage in $1-2^{\circ}$, the sprouts were partly yellow and decayed, in $2.5-1^{\circ}$ saleable. Sprouts from a temperature of $-5^{\circ}$ softend after melting, as did those in open boxes from $-2.5^{\circ}$ and $-5^{\circ}$. After 120 days' storage in MSAT-bags in $-1.5-1^{\circ}$ the sprouts were decayed, but in $-2.5^{\circ}$ still in relatively good condition.

The ascorbic acid content was examined after harvesting and after each storage period. The ascorbic acid content of Brussels sprouts at harvesting time varied from 99 to $198 \mathrm{mg} \%$ (fresh weight) depending on variety and season. The results of vitamin and dry matter determinations after storage periods of 30,60 and 120 days are shown in Tables 2 and 3 .

When Brussels sprouts were stored in MSAT-bags, the dry matter content was nearly unchanged after different storage periods. The ascorbic acid content lowered with the lengthening of the storage period and with lower storage temperature.

When the sprouts were stored in open boxes, the dry matter content was the higher the longer the storage period. The ascorbic acid content after 30 days' storage in $1-2^{\circ}$ was higher than at harvesting time. When the storage temperature was $-2.5^{\circ}$ or $-5^{\circ}$ the ascorbic acid content reduced rapidly. 